\title{
It Matters Who Does This Work: An Interview with Tonia Sutherland
}

\author{
Sophia Ziegler
}

\begin{abstract}
Tonia Sutherland (she/her) is assistant professor in the Library and Information Science Program at the University of Hawai'i at Mānoa. She serves on the SAA Council, and is author of the forthcoming book Digital Remains: Race and the Digital Afterlife. Dr. Sutherland holds a Ph.D. and an MLIS from the University of Pittsburgh's School of Computing and Information, as well as a BA in history, performance studies, and cultural studies from Hampshire College. Her work focuses on the interactions of technology and culture, and emphasizes critical work within the fields of archival studies, digital studies, and science and technology studies.

In this interview, recorded September 14, 2021, Sophia Ziegler talks to Tonia Sutherland about her work in critical digital librarianship, focusing specifically on her presentation during the LDL as Data Speaker Series in late 2019, as well as the new project, "Premised on Care: Redescription as Restorative Justice in American Archives." Ziegler and Sutherland also discuss the role of LIS education in creating a profession that is more prepared for the to describe content in a way that honors everyone's heritage.
\end{abstract}

Keywords: Restorative justice, archives, archival description, antiracism 


\section{INTERVIEW}

Sophie Ziegler: Tonia, thank you so much for taking the time to talk today. I'm really excited to be able to include this conversation in the inaugural issue of the Journal of Critical Digital Librarianship.

One of the broad topics that I was hoping you and I can discuss today is: Does it matter who does this work? In your presentation for the LDL as Data Speaker Series, ${ }^{1}$ you start by identifying three cases of digitized archival material having harmful content, and you introduce the idea of digital afterlives of these archival materials. You talked about college yearbooks, student newspapers, and the Harvard-held daguerreotypes of Renty and Delia. ${ }^{2}$ You also asked during your presentation why LIS professionals are so rarely part of the story. Why we, as LIS professionals, aren't flagging materials when they're being digitized, for instance, or when the metadata is being created. It seems to me that you might also want to argue that it matters who we have in the LIS profession, because not everyone will see the same harm everywhere. Is that fair to say?

Tonia Sutherland: That's absolutely fair to say. And I'm so glad you raised this because that's something that really is important to a lot of communities for a lot of reasons. And it's something that I'm hyperaware of here in Hawai'i. In Hawai'i, the only true experts on Native Hawaiians are - as it should be - Hawaiians. I wouldn't dare assume that I would best know how to represent Native Hawaiian materials. I certainly don't know enough 'Ōlelo Hawai'i (Hawaiian language) to be able to interpret in appropriate ways the material that is in front of me. Not to mention that there are multiple different modes of and approaches to knowledge construction. All of which impact how things get described or talked about. I think that there's already been so much harm and damage done in this community, which I am now a part of, but will always be an outsider to. And I raise Hawai'i as an example because of the uniqueness of the culture. Which is to say that, if you live in Hawai'i, you cannot call yourself Hawaiian. The only time that the word Hawaiian is used is in reference to Native Hawaiian - Kanaka Maoli - people, materials, ideas, etc. So if you live in Hawai'i, for a long time you might be called Kama'āina, which is 'common to the land,' or 'local to the land.' Otherwise you're just a resident of the state. You will never be Hawaiian. It's a way of understanding your

\footnotetext{
${ }^{1}$ Tonia Sutherland, "Tonia Sutherland | "Redescription as Restorative Justice" | \#LDLSpeakerSeries," Louisiana Digital Library, November 23, 2020, video, 1:02:56, https://www.youtube.com/watch?v=xOs r6D9INk.

${ }^{2}$ For more on the daguerreotypes of Renty and Delia, two enslaved individuals, and the ongoing repatriation effort, see: Matthew S. Schwartz, "Harvard Profits From Photos Of Slaves, Lawsuit Claims," NPR, March 21, 2019, https://www.npr.org/2019/03/21/705382289/harvard-profits-from-photos-of-slaves-lawsuit-clai ms; and Jarrett M. Drake, "A Vision of (In)Justice: Harvard Archives Bear a Strange Fruit," Medium, May 24, 2019, https://medium.com/@imddrake/a-vision-of-in-justice-harvard-archives-bear-a-strange-fruit-30e $\underline{645643 \mathrm{df} 6}$.
} 
role in a place that I think is really unique. If, for example, you move to New York and you're there for long enough, then you're a New Yorker. You move to wherever, you live there long enough, you can consider yourself a part of that place. It's just not the case here in Hawai'i at all.

So community engagement is something that's become a really critical aspect of working with librarians and archivists here in the islands because in terms of 'should only some people do this work,' or 'does it matter who does this work,' here it absolutely does. Again, I would never dream of speaking on behalf of a Native Hawaiian person. Rather, I work in collaboration and in community with Hawaiian people and allow their voices to come through because they are the ones who best understand. I'm using 'community engagement,' but I mean doing things in community, doing this work together.

So yes, it absolutely does matter and all of that is situational. And this is gonna sound bad, so you know, frame it however you want as you write this up, but do I, as a Black person in the United States - I'm a first generation American, the daughter of immigrants - do I necessarily trust a white man from a sundown town in Idaho (and no shade on Idaho, I'm just picking an example), someone who grew up in, say, a very small town in Idaho-do I trust them to understand my experience in a way that they could describe that experience? No, not necessarily. There is probably no single person with all of the expertise that's necessary to get all the descriptive work right. I really do genuinely believe that we need to be doing this work in community. In teams, whatever those teams look like.

Ziegler: To stay with this a little bit longer, during your presentation you cite a number of scholars and practitioners, most of whom are Black women, including Jessica Marie Johnson, Saidiya Hartman, Nikole Hannah-Jones, and Safiya Noble. While I was rewatching that, I was thinking about how, from my point of view, so much of the critical work being done in LIS and archives is being done by Black women and women of color. I'm thinking of Dorothy Berry, Sofia Leung, April Hathcock, Kaetrena Davis Kendrick, Fobazi Ettarh, Annie Pho, just to name a few, and there are so many others.

Do you feel like your interest in having LIS take a more active role in the afterlife of digital archival material overlaps with the seemingly constant effort at increasing diversity within the field?

Sutherland: Yes, yes. And thank you for framing it this way. I heard sort of the beginning of this question in your first question: Does it matter who does this work? And beyond the LIS aspect of it, the people who have been leaning into this work are largely-though certainly not entirely, as you and I both know - women, in particular of color, but people of color broadly and then folks that are allies. I want to be super clear that it's not just about ethnicity, race, nationality, but we also need to be taking gender and sexuality into consideration in these conversations too. Without straying into the politics of identity categories, I do think that the work that is being done, the impetus is coming from Black 
feminist-and other views of the world-situatedness. It's not necessarily about what skin somebody embodies, but what ethos they bring to the table.

And l've been encouraged to see that we're not talking about diversity in the same way anymore. What I'm seeing is a shift, it's a small shift, but there is a shift in the LIS profession. There are some folks who are just getting on board with ideas about diversity, but I think there is a core group of folks who have moved one step deeper into the analysis and are saying, 'Okay, well what does it look like if we bring Black feminist theory or queer theory to bear on our everyday practices? Not just on our scholarship, but in our actual, everyday practices?' And I think that that is necessarily changing the face of the profession. I think most of that isn't about there being new faces or voices, but about those faces and voices being given space to really exist and to be heard and be seen. I think these ideas have been here for a long time, and what we're seeing in terms of the profession is an opening up. I think that opening up is allowing things to bubble up. Things that have been percolating for a while but never had an opportunity to be in the center and held there as an idea that has value, or a positionality that has worth.

Ziegler: Unless I'm mistaken, I think I hear optimism in your description. Are you feeling optimistic about the future of the field?

Sutherland: You know, I really do. And I can say that with my whole chest. I can really say that I do. I think that I feel that optimism because I am seeing this bubbling up, I am seeing these openings, these faces, these voices. I was talking to Michelle Caswell at UCLA about archives, and I was expressing a bit of frustration about how there are so many folks who don't share the same vision. And we just had a really lovely conversation about how LIS and archives is a ship that's been sailing in one direction for so long. Archival education comes out of this very traditional French form of education ${ }^{3}$ and then from France it gets taken up in England and Australia and Canada and you see the overwhelming whiteness of the profession and we don't see ideas coming in from the Global South or the African continent or Asia. We've been sailing this big ship in one direction for so long, and Michelle made the point that it is a painful and slow turning, but the ship is turning. I can really see that. Every time I feel down or feel like, 'I don't know if we're actually making any progress,' I see this incremental turn. I hear those voices, I see those faces. I have a conversation like this with you. And I see that indeed, it may be slow and it may be painful, but this ship is turning. It is not sailing in the same direction full speed ahead, as it has been for centuries. I can really see and feel the energy acting against that and it fills me with a tremendous amount of optimism. I believe our future looks bright.

\footnotetext{
${ }^{3}$ https://en.wikipedia.org/wiki/\%C3\%89cole Nationale des Chartes
} 
Ziegler: I'm sure I'm not alone in needing a solid dose of optimism, so thank you for that. If you don't mind sticking with this topic for just a little while longer: I'm thinking about positionality. How do you think your own background prepares you for this type of work? For instance, in your SAA Council candidate statement you write, 'I identify as a queer Black woman who is the child of Caribbean immigrants and the first in my family to earn a college degree. ${ }^{4} \mathrm{I}^{\prime} \mathrm{m}$ guessing you would say that this puts you in a positionality that makes this work a central concern for you.

Sutherland: Absolutely. There aren't many other folks like me, who exist in all of those same intersections in the LIS field in the United States - which is not to say there aren't any. For me, and I think I say this in my statement, I really had to advocate for myself along so many different axes over time, and that type of advocacy has really become central to how I understand my work.

I'm also the oldest of three children. My parents didn't raise me to be a person who only advocates for myself. So there's the, 'You look out for your little brothers.' When my youngest brother was born, my mother was like, 'This is the only brother you're ever going to have.' Well, little did she know! But it was always, 'Look out for your little brothers,' and I really did take that to heart as a kid, and I take it to heart now. It's the lift-as-you-climb attitude. I'm telling it from a personal perspective, but some of that is also a Black feminist ethos, a Black feminist perspective. I think it's also very much a queer ethos and perspective. The places where those things intersect are the areas where, in my experience, folks fall into the cracks and don't get seen. And those are the cracks that we want the bubbles to come from, we want the voices to bubble up from. And so I think my own positionality has increased my desire to be an advocate. And also I will also say that there have been people who have looked out for me. I have been lifted up, I have been held. I have been cared for.

So, yes, I think partly it's who I am. Partly it's my unique 'I don't feel like I fit here because of this,' or 'I don't feel like I fit here because of that,' I'm always looking for where I belong. And because of that, I'm looking for and finding community wherever I can. And I want to give back in the same ways I was given to. That lifting, that climbing. I think that type of positionality, partly it's just endemic to who I am, but partly, again, it's experiential and that's the ethos I bring with me to the work always. If I'm not doing that then I don't feel like I'm doing my job. Or at least, I'm not doing it very well.

Ziegler: I think that sentiment segues nicely into your new project, funded by the Institute of Museum and Library Services (IMLS). "Premised on Care: Redescription as Restorative Justice in American Archives" takes so much of the work that you've been doing and tries to think about how to expand it broady so we can learn from each other and all learn together. I wonder if you'd be willing to say a little bit about this project.

\footnotetext{
${ }^{4}$ For the full Candidate Statement, see: "Tonia Sutherland, Candidate for Council," Society of American Archivists, last modified March 2, 2021, https://www2.archivists.org/governance/election/2021/Sutherland.
} 
Sutherland: I'm really excited about it. I'm thrilled that IMLS and the reviewers thought it was a worthwhile project to fund, especially right now in this moment. I'm going to say it was maybe 2015, 2016, there was a conversation that was happening on Twitter. I was thinking about these kinds of issues around description because I was teaching. I teach Archival Representation, Access, and Use. (I've been teaching that class for ten years now and I love it.) But for the representation part of it, I would teach students a whole swath of thesauri: 'Look at this, look at that, these are all the tools that we have for our descriptive practices.' But it wasn't enough. And then in 2015 I was teaching at the University of Alabama, and there was a group coming out of London, or somewhere in the United Kingdom, somewhere in England. A group of doctoral students who had put together a conference, it may have been a one-day kind of meet up where the hashtag coming out of it was \#racistrecords. If you go and you actually look at the hashtag \#racistrecords there's not much there, but that was the hashtag they were using and I thought, 'Oh, I'm not the only person thinking about this; this is great. ${ }^{5}$

I thought at the time, I'd really like to write up a grant to study this, to see if there are people out there who are actually doing redescriptive kind of work. Are there folks who are taking up redescription as a central part of their work process? And if so, what does that look like? It took me a while; I changed jobs in there and started a new position. I put out a call on Twitter, just a quick feeler to see how many folks are out there doing this kind of work. And I was so encouraged by the response. It was the American Philosophical Society, I heard from the Louisiana Digital Library, I heard from some folks at UCLA and UC Riverside, and I thought, 'Okay, there are some people who are thinking about this and actually doing this kind of work.' And then Archives for Black Lives Philadelphia put out their Anti-Racist Description Resources ${ }^{7}$, and I thought, 'Okay we actually need an empirical study. We need to know who's doing this and what kinds of projects exist around description and redescription.'

So this grant from IMLS is designed to do this empirical work. To really find out what folks are doing, what role digitization plays in that, at what point decisions get

\footnotetext{
${ }^{5}$ At the time of this writing, there seem to be multiple years' worth of \#racistRecords tweets that refer to the gathering discussed here, but the reader is also warned that other content is also gathered under that hashtag. To see tweets tagged \#racistRecords, visit:

https://twitter.com/search?q=racistRecords\&src=typed querv\&f=top

${ }^{6}$ Tonia Sutherland (@toniasutherland), "Question for \#archivestwitter: do y'all know of redescription efforts underway at any US repositories (large, small, community, institutional-doesn't matter)? I know A4BL Philly and UCLA Library Spec Coll have done some of this work. Anyone else? \#critarch," Twitter, February 10, 2020, https://twitter.com/toniasutherland/status/1227073206311251968.

${ }^{7}$ Alexis A. Antracoli, Annalise Berdini, Kelly Bolding, Faith Charlton, Amanda Ferrara, Valencia Johnson, and Katy Rawdon, "Archives for Black Lives in Philadelphia: Anti-Racist Description Resources" (Archives for Black Lives in Philadelphia's Anti-Racist Working Group, October 2019, updated September 2020), https://archivesforblacklives.files.wordpress.com/2020/11/ardr 202010.pdf.
} 
made, at what point we might be able to intervene or interject, what would be the most appropriate point, what kind of advice can we give folks who are interested in taking a look at their collections and maybe updating some of their description. And I really do think about it as reparative work and restorative justice. The language that we use to talk about people, words matter. And not just people, but events. And I think that if we can reframe things in a way that is more-I have just a whole, like, thesaurus of words that just popped in my head - I want to say generous, I want to say generative, I want to say appropriate, I want to say thoughtful, careful, compassionate, loving, true, honest, fair. I'm grateful for the opportunity to do this study because I think what will come out of it is just better practice and less harm. I think that there's a real chance to repair some harm here and that feels good, that feels like doing the work right.

Ziegler: I feel like I know a lot of people doing work like this, I also know a lot of people who say their institution wouldn't really be on board with it. The work of the grant will be studying the work that is already happening; are you hoping that it will also create a set of best practices?

Sutherland: So I think advocacy is going to be a huge part of what comes out of this. We'll look not only at existing processes, procedures, policies, but also barriers to success. Barriers to getting programs off the ground. A lot of those barriers are going to be human barriers, and some of them are going to be fiscal. I really believe that money is not an insignificant resource, and resources are not an insignificant consideration. I think there's a certain amount of resistance, and some of that again goes back to resources. I think people are like, 'Look I have a limited amount of money and I have a small staff and what is the best use of my resources? Things that will bring in more resources.' It's just the reality of the situation. How do we advocate for this redescription work to be done in a way that makes it clear that it is a value add? Doing this kind of work is actually adding value to your collections. I think that's going to be a big part of the work. But those aren't the only reasons people resist, so I think finding out what the other reasons are and really coming up with some solutions... Well, that's the slow turning of the ship part, right?

Ziegler: That's exactly what I was going to draw attention to as well. As a practicing archivist, I've been in the field for about twelve years, and honestly I feel like ten years ago these changes would have seemed absolutely impossible. So I do feel like it speaks to a turning of the archives ship, as we've been describing it, and to the extent that it already has turned. There are so many people to talk to who are doing this work already.

Sutherland: Yes, I agree. Five or six years ago it was shocking to know even one other person who was thinking about this. And now that I have twenty institutions or so that I can speak to who have people who have done this type of work on some level, or where 
it has become apparent that they need to do this type of work on some level, it speaks to the turning of the ship.

Ziegler: One last category of discussion that I was hoping we would touch on is the future of critical digital librarianship. As you know, this interview will be included in the first issue of the Journal of Critical Digital Librarianship, which is a new journal intended to act as a central point for work that explores many of the topics we've been discussing, such as redescription and digital archival material as sites of restorative justice. Here at the beginning of this venture, I find myself thinking a lot about critical digital librarianship, and what that might mean in ten or twenty or more years. And how the work we do now can affect that future. And I wonder, where do you see the future of redescription going, and what new futures do you hope your work will open?

Sutherland: That's a really good question. I would like to see redescription be taught as part of any LIS program. I'd like to see it become one of the central tenets of what we teach, in the same way we teach metadata and cataloging and reference. There's remediative work that needs to be done in a lot of our collections, especially as we're still moving material from analog to digital environments. I think with born-digital material we are already paying closer attention to our descriptive practices from the beginning. So my hope is that redescription will become less and less necessary as time goes on. Decades from now, hopefully there will be less redescription work to do because our descriptive practices will become better, will become stronger, we'll be more critical-- especially at that moment of being or becoming digital, whether it's born-digital or being digitized. I would hope that we would get so much better at our descriptive practices that down the line redescription won't be necessary. I hope that 'redescription' is a word a hundred years from now that we're not talking about because we've done such a good job.

Ziegler: As someone who teaches students how to be archivists, librarians, and LIS professionals, do you feel like there needs to be a significant social shift, such that people going through the program will be able to have the necessary cultural competency? What would we have to do to prepare the profession in a way that won't require redescription in the future? Is there a way that we can make sure that everybody is attuned enough to what's happening to be cognizant of harmful descriptions?

Sutherland: One hundred percent. I can talk about what we've done at the University of Hawai'i at Mānoa. We have six student learning outcomes, and they are mapped directly to ALA's core competencies. ${ }^{8}$ The ALA is working on a new version now, and one of those

8 "ALA's Core Competencies of Librarianship," approved and adopted by the ALA Council January 27, 2009, https://www.ala.org/educationcareers/sites/ala.org.educationcareers/files/content/careers/core comp/corecompetences/finalcorecompstat09.pdf. 
core competencies is about Social Justice. And so I think that if LIS programs, working in concert and collaboration with our professional organizations and our accrediting bodies, if we make it important to the field then it kind of fans out. And no, it's not going to reach every single school and every single program in the same way. As I talked about, the way that LIS is taught in Hawai'i is very geographically and culturally specific. It needs to be because we're training librarians and archivists to work in this cultural context. The folks that go to Alabama or lowa or Pitt or other places are going to have different cultural competencies that they need to walk away with. So on one hand I want to say that the ALA core competencies, and Social Justice being one of them, has the potential to really impact and influence the way LIS is taught, making cultural competency a central idea. How that gets interpreted is where we might have to do a little more advocacy work.

But I definitely do think that not only does the way we train librarians and archivists need to change, but I would say it is changing. I think five years ago people were absolutely shocked to hear that, in my introduction to archives classes, I wasn't teaching Jenkinson and Schellenberg. I just don't teach them. There are other perspectives, there are other ways to understand records, other ways to understand archives, and the role that they play in society. I mention Jenkinson and Schellenberg as one way of thinking about it, but I no longer teach that it's the way. And I think increasingly that the same ship turning that we are feeling and seeing, I think that's happening in the classroom too. I know for sure that my archives friends and colleagues who are teaching and training the next generation of archivists, that these are the kinds of things that they are bringing into the classrooms. Again, I'm encouraged and optimistic.

Ziegler: I really appreciate your perspective as an educator, Tonia; I really appreciate your time.

Sutherland: I'm really grateful for the questions that you asked and for the opportunity to think about the work in a way that is about optimism and potential and possibility. It's both a retrospective look at where we've been, where we are now, and where we have the potential to go. I'm left feeling super positive, and grateful for this conversation. So, thank you! 


\section{BIBLIOGRAPHY}

"ALA's Core Competencies of Librarianship." Approved and adopted by the ALA Council January 27, 2009.

https://www.ala.org/educationcareers/sites/ala.org.educationcareers/files/cont ent/careers/corecomp/corecompetences/finalcorecompstat09.pdf.

Antracoli, Alexis A., Annalise Berdini, Kelly Bolding, Faith Charlton, Amanda Ferrara, Valencia Johnson, and Katy Rawdon. "Archives for Black Lives in Philadelphia: Anti-Racist Description Resources." Archives for Black Lives in Philadelphia's Anti-Racist Working Group, October 2019, updated September 2020. https://archivesforblacklives.files.wordpress.com/2020/11/ardr 202010.pdf.

Drake, Jarrett M. "A Vision of (In)Justice: Harvard Archives Bear a Strange Fruit." Medium, May 24, 2019.

https://medium.com/@jmddrake/a-vision-of-in-justice-harvard-archives-bear-astrange-fruit-30e645643df6.

Schwartz, Matthew S. "Harvard Profits From Photos Of Slaves, Lawsuit Claims." NPR, March 21, 2019.

https://www.npr.org/2019/03/21/705382289/harvard-profits-from-photos-of-sl aves-lawsuit-claims.

Sutherland, Tonia. "Tonia Sutherland | "Redescription as Restorative Justice" | \#LDLSpeakerSeries." Louisiana Digital Library. November 23, 2020. Video, 1:02:56. https://www.youtube.com/watch?v=xOs r6D9INk.

Society of American Archivists. "Tonia Sutherland, Candidate for Council." Last modified March 2, 2021.

https://www2.archivists.org/governance/election/2021/Sutherland. 